\title{
The role of sacroiliac joint steroid injections in the treatment of axial spondyloarthritis
}

\author{
Serdar Kokar' (D), Önder Kayhan¹(D), Savaş Şencan² (D), Osman Hakan Gündüz² (D) \\ ${ }^{1}$ Department of Physical Medicine and Rehabilitation, Marmara University Faculty of Medicine, Istanbul, Turkey \\ ${ }^{2}$ Department of Physical Medicine and Rehabilitation, Division of Pain Management Section, \\ Marmara University Faculty of Medicine, Istanbul, Turkey
}

\section{ABSTRACT}

Objectives: This study aims to investigate the effects of fluoroscopy-guided sacroiliac joint steroid injection in patients with acute bilateral sacroiliitis diagnosed with axial spondyloarthritis ( $\mathrm{axSpA}$ ) and how those injections affect the current need for nonsteroidal anti-inflammatory drug (NSAID) usage.

Patients and methods: We retrospectively evaluated 43 patients ( 28 males, 15 females; mean age, $31.7 \pm 6.3$ years; range, 18 to 44 years) fulfilling the Assessment of SpondyloArthritis international Society 2009 criteria for axSpA between June 2015 and May 2016. One group included 22 patients (injection group) treated with sacroiliac joint steroid injection (triamcinolone acetonide) and the other group included 21 patients (non-injection group) not receiving the injection. All 43 patients in both groups were treated with indomethacin peroral. Pre-treatment, first week and first, third and sixth month follow-up examinations were evaluated.

Results: $A \geq 50 \%$ reduction in the numeric rating scale score compared with the baseline was considered as significant pain relief. The mean pain relief rates in patients receiving injections were higher at all inspections. This difference was statistically significant at first week ( $<<0.05)$. When groups were compared, no difference was found in the Bath Ankylosing Spondylitis Disease Activity Index scores ( $p>0.05$ ). There was no statistically significant difference between the two groups when indomethacin dose was evaluated cumulatively for six months ( $p>0.05$ ).

Conclusion: Fluoroscopy-guided sacroiliac joint steroid injections can be recommended in patients with active sacroiliitis, particularly in those with severe axial pain, for rapid analgesia in the initial term. It was concluded that steroid injections applied to the sacroiliac joint did not affect disease activity. It is noteworthy that there is a trend to reduce the use of NSAIDs in patients receiving these injections, although it does not make a statistically significant difference in the long term.

Keywords: Axial spondyloarthritis, fluoroscopy, intraarticular injection, sacroiliac joint, sacroiliitis.

Sacroiliitis, which is a cause of inflammatory back pain, is often the first symptom of axial spondyloarthritis (axSpA). If it is not treated properly and continues for many years, joint ankylosis can develop. Along with ankylosis, pain and movement restriction and impairment in the functional status of the patient occur. ${ }^{1}$
Two main groups of drugs are used in the pharmacological treatment of patients with axSpA: nonsteroidal anti-inflammatory drugs (NSAIDs) and tumor necrosis factor-alpha (TNF- $\alpha$ ) blockers when the patient does not respond adequately to NSAIDs. ${ }^{2}$ NSAIDs are believed to reduce radiological progression, and these are still the

Received: January 25, 2020 Accepted: May 25, 2020 Published online: January 14, 2021

Correspondence: Serdar Kokar, MD. İstanbul Üniversitesi Cerrahpaşa-Cerrahpaşa Tıp Fakültesi Fiziksel Tıp ve Rehabilitasyon Anabilim Dalı, Ağrı Yönetimi Bölümü, 34098 Fatih, İstanbul, Türkiye. Tel: +90 541 - 6415143 e-mail: srdrkkr@hotmail.com 
first option in treatment. ${ }^{2,3}$ However, sometimes they are insufficient in controlling the disease, while side effects may occur with long-term use. On the other hand, anti-TNF treatment should be applied with caution considering increased susceptibility to various infections, the possibility of developing neurological and/or hematologic side effects, their effects on the cardiovascular system, and even their association with cancer development, although this still remains controversial. ${ }^{4,5}$ Therefore, anti-TNFs seem to be an aggressive option, particularly in patients with SpA who do not have significant clinical signs other than sacroiliitis. In such cases, oral steroids have no place; however, local steroid injections into the sacroiliac joint emerge as an alternative treatment option. ${ }^{6}$ Questions regarding their effect on clinical and functional parameters, which patients should be administered and when, and how they influence the need for current anti-inflammatory therapy still need answers. The results on these topics are controversial, and analysis of the literature is difficult. A recent review also highlighted the limitations of the studies published so far and emphasized the shortcomings such as the great heterogeneity of the procedure (injection technique, pharmacologic product injected), the lack of detailed information about the phenotype of SpA, and global disease activity level. ${ }^{7}$ Moreover, factors such as non-homogeneous patient groups, narrow exclusion criteria, and undocumented NSAID use in the majority of studies in the literature indicate the need for further research.

In this study, we aimed to investigate the effects of fluoroscopy-guided sacroiliac joint steroid injection in patients with acute bilateral sacroiliitis diagnosed with axSpA and how those injections affect the current need for NSAID usage.

\section{PATIENTS AND METHODS}

The data of consecutive patients who were referred to Marmara University Research and Application Hospital, Department of Physical Medicine and Rehabilitation, pain medicine section outpatient clinics between June 2015 and May 2016 were evaluated retrospectively.
Patients were newly diagnosed with axSpA according to the Assessment of SpondyloArthritis international Society (ASAS) 2009 criteria. $^{8}$ Forty-three patients (28 males, 15 females; mean age, $31.7 \pm 6.3$ years; range, 18 to 44 years) meeting the inclusion criteria were included in the study. Inclusion criteria were as follows: 18-45 years of age at the time of admission; bilateral active sacroiliitis detected with sacroiliac magnetic resonance imaging (MRI); ${ }^{9}$ at least four positives out of five sacroiliac pain provocation tests supporting that the pain was originated from the sacroiliac joint, ${ }^{10}$ having received a combination of sacroiliac joint steroid injection under fluoroscopy, indomethacin, and exercise therapies; or having received indomethacin and exercise therapies without injection. Exclusion criteria were as follows: advanced-stage ankylosing spondylitis (AS) (patients with Stage 4 sacroiliitis according to the modified New York criteria), use of NSAIDs other than indomethacin, use of anti-TNF therapy before or during admission, pregnancy or lactation at the time of diagnosis, presence of peripheral arthritis or uveitis in the six months after being enrolled to the follow-up program, presence of psoriasis, inflammatory bowel disease or pyogenic sacroiliitis, patients considered to have reactive arthritis, use of oral or parenteral steroids within three months before the initiation of treatment, history of corticosteroid injection into the sacroiliac joint within the last six months, patients at high risk for high-dose NSAID use (renal insufficiency, cardiac instability, etc.), and patients with exercise intolerance. The study protocol was approved by the Marmara University Medical Faculty Ethics Committee (Protocol code: 09.2016.322). A written informed consent was obtained from each patient. The study was conducted in accordance with the principles of the Declaration of Helsinki.

Two different patient groups were created in this context: patients treated with fluoroscopy-guided sacroiliac joint steroid injection (injection group, $\mathrm{n}=22$ ) and patients followed-up without injection (non-injection group, $\mathrm{n}=21$ ). The participants in both groups were patients who received indomethacin $25 \mathrm{mg}$ oral capsule and exercise therapy.

Anteroposterior pelvis X-rays were also evaluated in our study, and the patients were divided into subgroups of AS and non-radiographic 
axSpA (nr-axSpA) according to the modified New York criteria. ${ }^{11}$

The NSAID treatment is initiated in all patients who are diagnosed with axSpA in the physical medicine and rehabilitation $(\mathrm{PM} \& \mathrm{R})$ clinic and who do not have any comorbid diseases that will pose a contraindication. Patients are instructed to use these drugs on the basis of their pain levels without exceeding the maximum dose. In addition, each patient is required to note the daily NSAID use. Side effects and drug changes are noted in the patient files. We included patients who were treated with indomethacin $25 \mathrm{mg}$ oral capsule as the first-line therapy in order to create a similar sample.

Furthermore, all patients diagnosed with axSpA receive hands-on training from an expert physiotherapist for a daily home exercise program. The program comprises joint range of motion and muscle strengthening exercises, exercises to strengthen spinal extensor and back extensors, stretching exercises for hamstring and hip flexors, and deep breathing exercises to preserve or increase chest expansion.

Axial pain having been graded between 0 and 10 using a numeric rating scale (NRS) at each examination of the patients was evaluated. A $\geq 50 \%$ reduction in the NRS score compared with baseline was considered a significant pain relief. ${ }^{12}$

Bath Ankylosing Spondylitis Disease Activity Index (BASDAI) forms ${ }^{13}$ having been filled by the patients were included in the evaluation. Schober, modified Schober, chest expansion, hand-ground distances, and the level and duration of morning stiffness having been recorded at the time of admission and at first week, and first, third and sixth months after initiation of treatment were also evaluated.

From our clinical observations, we notice that pain relief occurs after sacroiliac joint steroid injection in patients diagnosed with active sacroiliitis. We suppose that these injections provide pain relief apart from the NSAIDs. Moreover, we are in the opinion that NSAID usage and corresponded complications may decrease after reducing the pain. Therefore, in addition to prescribing NSAIDs in the PM\&R clinic as the main treatment, we pain specialists also recommend sacroiliac joint steroid injections to patients at baseline. Nevertheless, we inform the patients about the details though it is a minimally invasive procedure and allow them to decide on whether or not to undergo the intervention. Fluoroscopy-guided sacroiliac joint steroid injections are performed in our clinic by a pain management specialist with more than 10 years of experience. These patients are placed in the prone position; skin is wiped three times with a povidone-iodine solution and covered with sterile covers. The $\mathrm{C}$-arm is angled 25-35 degrees caudally from the axial plane on average and with 0-30 degrees medial oblique rotation so as to clearly visualize the posteroinferior angle of the sacroiliac joint. After the joint is displayed, the needle insertion point in the inferior section, which is the synovial part, is determined. Local anesthesia is performed with $3 \mathrm{~mL}$ of prilocaine. After capturing an image in the coaxial plane according to the X-ray direction, a 22G, 3.5-inch spinal needle is advanced and inserted into the sacroiliac joint under intermittent fluoroscopy, and intra-articular placement is confirmed by injecting $0.5 \mathrm{~mL}$ of iohexol (Figure 1). Half of the mixture of $80 \mathrm{mg}$ of triamcinolone acetonide and $1 \mathrm{~mL}$ of $0.5 \%$ bupivacaine is administered, and than the same procedure is applied to the other sacroiliac joint. Patients without complications are discharged and advised to attend follow-up visits.

\section{Statistical analysis}

Statistical analyses were performed by using the IBM SPSS version 23.0 software

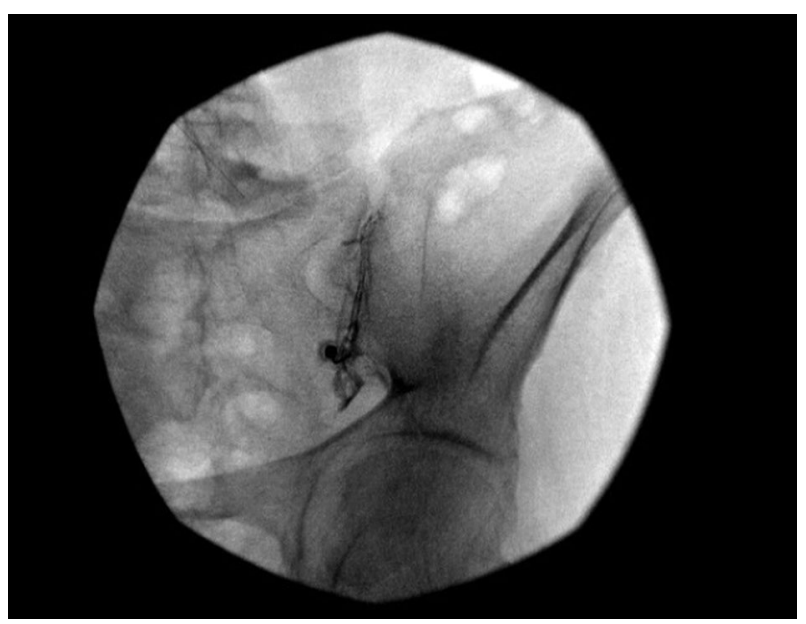

Figure 1. Sacroiliac joint injection with contrast spread. 
(IBM Corp., Armonk, NY, USA). Visual (histogram and probability graphs) and analytical (Kolmogorov-Smirnov/Shapiro-Wilk tests) methods were used to test whether the variables were normally distributed. Comparison of demographic and clinical variables of groups was performed by using the unpaired t-test. For variables not normally distributed, Mann-Whitney U test was performed. Repeated measurements were analyzed by using the Friedman test because they did not show a normal distribution.
At each follow-up examination, 1.1-point difference in comparison with the baseline score of BASDAI for patients with active disease (BASDAI score $\geq 4$ ) and 1.2-point difference for patients with inactive disease (BASDAI score $<4)$ were considered adequate for a minimum clinically important improvement (MCII). ${ }^{14}$ For comparing the proportions of patients who had at least a 50\% reduction in the NRS score in comparison to the baseline, and for patients who attained the MCII according to the BASDAI

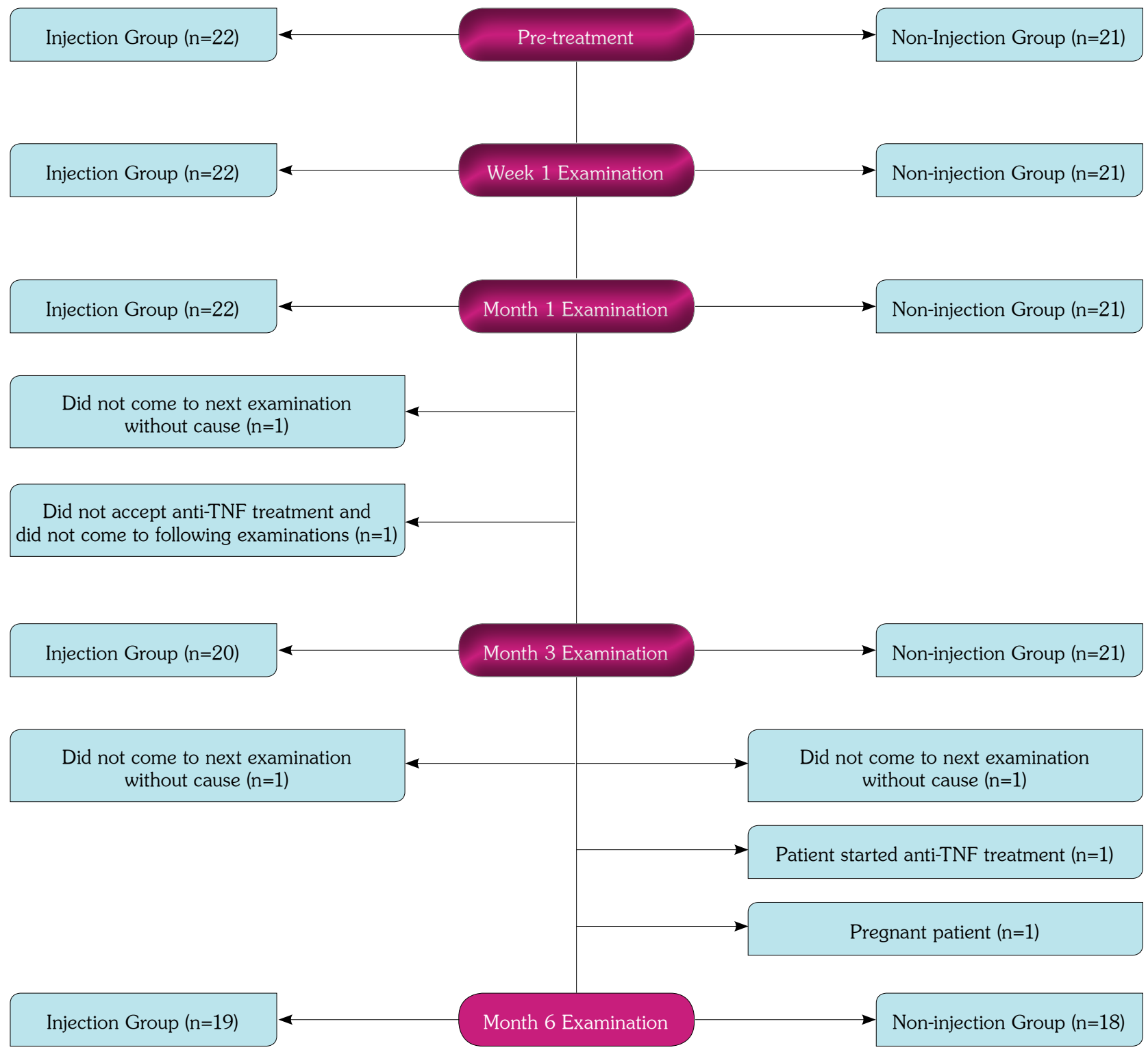

Figure 2. Participant flow diagram.

TNF: Tumor necrosis factor. 


\begin{tabular}{|c|c|c|c|c|c|}
\hline \multirow[b]{3}{*}{ Reduction in NRS score } & \multicolumn{4}{|c|}{ Study groups } & \multirow[b]{3}{*}{$p$} \\
\hline & \multicolumn{2}{|c|}{ Non-injection } & \multicolumn{2}{|c|}{ Injection } & \\
\hline & $\mathrm{n}$ & $\%$ & $\mathrm{n}$ & $\%$ & \\
\hline $\begin{array}{l}\text { Week } 1 \\
\quad<50 \\
\geq 50\end{array}$ & $\begin{array}{l}10 \\
11\end{array}$ & $\begin{array}{l}47.6 \\
52.4\end{array}$ & $\begin{array}{c}2 \\
20\end{array}$ & $\begin{array}{c}9.1 \\
90.9\end{array}$ & 0.013 \\
\hline $\begin{array}{c}\text { Month } 1 \\
\quad<50 \\
\geq 50\end{array}$ & $\begin{array}{c}12 \\
9\end{array}$ & $\begin{array}{l}57.1 \\
42.9\end{array}$ & $\begin{array}{c}6 \\
16\end{array}$ & $\begin{array}{l}27.3 \\
72.7\end{array}$ & 0.094 \\
\hline $\begin{array}{c}\text { Month } 3 \\
\quad<50 \\
\geq 50\end{array}$ & $\begin{array}{l}10 \\
11\end{array}$ & $\begin{array}{l}47.6 \\
52.4\end{array}$ & $\begin{array}{c}5 \\
15\end{array}$ & $\begin{array}{l}25.0 \\
75.0\end{array}$ & 0.239 \\
\hline $\begin{array}{c}\text { Month } 6 \\
\quad<50 \\
\geq 50\end{array}$ & $\begin{array}{c}10 \\
8\end{array}$ & $\begin{array}{l}55.6 \\
44.4\end{array}$ & $\begin{array}{c}6 \\
13\end{array}$ & $\begin{array}{l}31.6 \\
68.4\end{array}$ & 0.255 \\
\hline
\end{tabular}

scores, Yates correction for continuity was used in analyses of $2 \times 2$ contingency tables. All other categorical variables were analyzed by using the Pearson chi-square test or the Fisher's exact test. $\mathrm{P}$ values $<0.05$ were considered statistically significant.

\section{RESULTS}

Duration of symptoms/month was $5.5 \pm 3.4$ in the injection group (mean age $33.4 \pm 5.9$ years; range, 23 to 44 years) and $6.7 \pm 3.8$ in the non-injection group (mean age, 29.9 \pm 6.2 years; range, 18 to 43 years). Both groups were similar with regard to demographic data (age, sex, socioeconomic status, and work status), AS/nr-axSpA patient ratio, and symptom duration $(p>0.05)$. The participant flow diagram is presented in Figure 2.

The rate of patients with significant pain relief was higher in the injection group at all inspections and this difference was statistically significant at first week $(p<0.05$, Table 1$)$. The NRS score changes from baseline to other follow-ups are presented in Figure 3.

There was no statistically significant difference between two groups when indomethacin dose was evaluated cumulatively for six months. However, there was a tendency to use higher doses of the drug in the non-injection group at all time intervals, more prominent in the early period ( $p>0.05$, Figure 4).

When both groups were compared, no difference was found in the BASDAI score changes (Table 2), duration of morning stiffness (minute), erythrocyte sedimentation rate (ESR) ( $\mathrm{mm} /$ hour), and C-reactive protein (CRP) changes at first week, and first, third and sixth months ( $p>0.05$ for all).

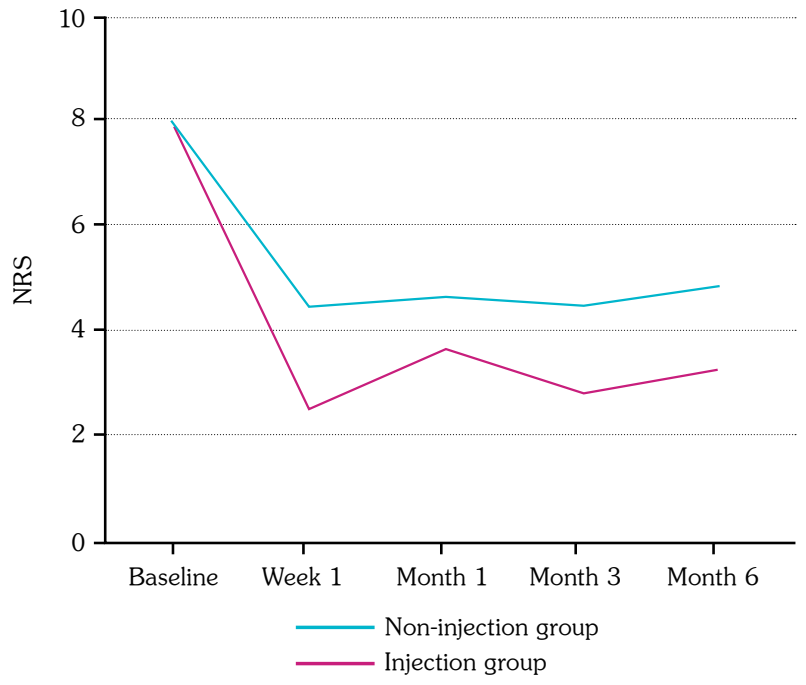

Figure 3. Numeric rating scale score changes from baseline to other follow-ups. NRS: Numeric rating scale. 


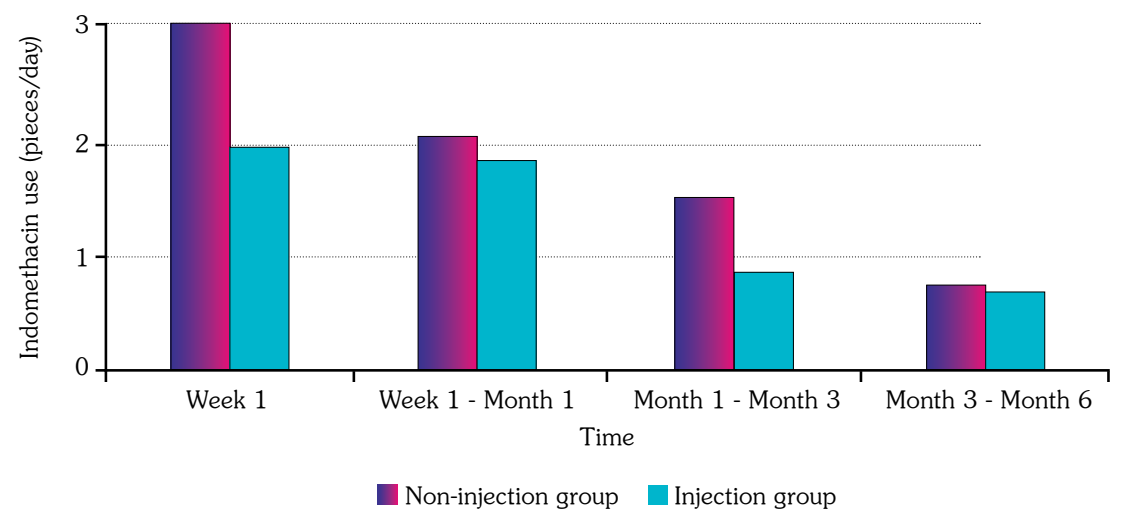

Figure 4. Indomethacin use $25 \mathrm{mg}$ capsule/pieces/day.

Table 2. Evaluation of improvement of disease activity by using Bath Ankylosing Spondylitis Disease Activity Index

\begin{tabular}{lccc}
\hline & \multicolumn{3}{c}{ Study groups } \\
\cline { 2 - 3 } BASDAI improvement & Injection $(\mathrm{n}=22)$ & Non-injection $(\mathrm{n}=21)$ & $p$ \\
\hline Week 1 (\%) & 77.3 & 66.7 & 0.664 \\
Month 1 (\%) & 68.2 & 76.2 & 0.806 \\
Month 3 (\%) & 63.6 & 71.4 & 0.826 \\
Month 6 (\%) & 63.6 & 70.0 & 0.913 \\
\hline BASDAI: Bath Ankylosing Spondylitis Disease Activity Index. & & \\
\end{tabular}

When patients with AS and nr-axSpA were compared in terms of NRS score changes and drug use, no difference was found between the groups at any time point ( $p>0.05)$.

\section{DISCUSSION}

In the present study, significant pain relief ( $a \geq 50 \%$ reduction in the NRS score) in the injection group was detected at $90.9 \%$ of the patients at the end of the first week. Following the examinations at first, third and sixth months, this rate was found to be reduced as $72.7 \%, 71.4 \%$, and $65 \%$, in turn. The results have shown that these injections are more effective in short term, yet the impacts decline afterwards. However, the mean pain relief rates in patients receiving injections were higher at all inspections than the non-injection group. This difference was statistically significant at first week. The first study investigating the effect of fluoroscopy-guided corticosteroid injection in patients with SpA was performed by Maugars et al. ${ }^{12}$ Pain relief was observed in $19(79.2 \%)$ of 24 patients receiving the injection, and the duration was reported as $8.4 \pm 4.5$ months (range, 1 to 15 months). On the other hand, in the study, 16 patients were diagnosed with AS, five with axial psoriatic arthritis, one with Crohn's disease, and two with SpA associated with palmoplantar pustulosis, which may have complicated the interpretation of the results. ${ }^{12}$

In their study, Maugars et al. ${ }^{15}$ reported that 18 of 19 patients benefiting from the injection used NSAID before injection, eight of these patients stopped using the medication after injection, and six of them decreased the dose. However, they reported that all patients with recurrent pain either resumed their medication or increased the dose. Karabacakoğlu et al. ${ }^{16}$ reported a reduction of at least 50\% in the NSAID use in 13 (76.4\%) of 17 patients and a lesser reduction in two (11.7\%) 
patients after receiving sacroiliac joint steroid injections. They reported that two patients (11.7\%) stopped using NSAIDs after injection. However, they did not report when this reduction in drug use started and how long it continued. In a previous study, Bollow et al. ${ }^{17}$ applied computed tomography-guided corticosteroid injections into 103 sacroiliac joints of 66 patients with SpA. According to their results, 39 patients decreased the NSAID dose by $\geq 50 \%$ and eight patients completely stopped the drug treatment; this was sustained for months. However, the duration of this marked reduction in drug use was not precisely reported. Furthermore, in all three aforementioned studies, information on the amount of NSAID use was obtained verbally from the patients based on estimation; therefore, the data may be misleading. ${ }^{15-17}$ In our clinic, patients are instructed to use medications on the basis of their pain level without exceeding the maximum dose and to record their daily use of NSAIDs. This gives us documented objective data on the amount of drug use. In our study, the amount of drug (indomethacin) use (pieces/day) was found to be higher in the non-injection group. However, there was no statistically significant difference in indomethacin use between the groups based on the six-month cumulative dose evaluation. Furthermore, it is unknown whether patients were using medication for reasons other than SpA-associated inflammatory pain, and this can be considered a limitation of the present study. Side effects may also have developed in patients during NSAID use. It is possible that these side effects led to dose changes. This can be expressed as another limitation of the present study.

Maugars et al. ${ }^{12}$ reported that injections produce better results in patients with a shorter disease duration. In our study, there was no significant difference between patients with AS and $n r-a x S p A$ in terms of changes from baseline in NRS scores at first week, and first, third, and sixth month. From this point of view, we consider that disease activity rather than disease duration or chronic changes may have affected the results.

In our study, we found that sacroiliac joint steroid injections had no effect on ESR and CRP levels. In this respect, our results contradict those of Bollow et al. ${ }^{17}$ but seem to be consistent with those of Günaydın et al. ${ }^{18}$ Considering our results, we think that the systemic effect of these injections is weak.

Clinically remarkable improvement was calculated based on the study of Kviatkovsky et al. ${ }^{14}$ by using the BASDAI scores. Accordingly, there was no significant difference between the two groups in any time frame. In this respect, it was concluded that steroid injections applied to sacroiliac joint did not affect disease activity.

When we examined morning stiffness, Schober measurement and hand-ground distance values at patient follow-ups, we found no relationship between these parameters and treatment methods. From this point of view, our results are consistent with those of other studies. ${ }^{15,18}$

When patient data were retrospectively reviewed, it was found that anti-TNF treatment was initiated in one patient at third month in the non-injection group and one patient at sixth month in the injection group on the basis of the ASAS recommendations on the use of anti-TNF in patients with axSpA updated in 2010. ${ }^{19}$ These patients did not benefit from other treatment modalities, could not reduce NSAID dosage due to pain, and had a high disease activity index (BASDAI >4).

In their study, Plastaras et al. ${ }^{20}$ reported side effects after 191 fluoroscopy-guided sacroiliac joint injections. Accordingly, they considered fluoroscopy-guided sacroiliac joint injection as a safe method with minimal side effects. When the side effects recorded in our study were examined, injection site pain (9.1\%) was observed in only two patients. In this regard, we agree with Plastaras et al. ${ }^{20}$

On the other hand, particularly in pregnant and other patients whose NSAID use is contraindicated, recurrent corticosteroid injections should be kept in mind to performed. However, we remind that ultrasound should be preferred to fluoroscopy as an imaging tool while performing injections in pregnant patients.

The strengths and distinctive features of our study include homogeneous patient groups, all injections being performed bilaterally, broad exclusion criteria, and objective and documented presentation of NSAID use. The limitations 
of this study are its retrospective design as well as the need for a larger sample size to provide objective data on how sacroiliac joint steroid injections affect the initiation of anti-TNF treatment. Besides, although the determination of sacroiliitis on sacroiliac MRI and at least four positives out of five sacroiliac pain provocation tests were included in the inclusion criteria, the lack of precise exclusion of other possible causes of low back pain can be considered as another limitation. We determined that pain can be reduced in a significant part of the patients with this treatment option, particularly in the early period. In this respect, sacroiliac joint steroid injections can be considered as a valuable treatment alternative in cases with severe pain for rapid analgesia. However, we would like to emphasize that interpreting this relief as a treatment success in spondyloarthritis is not entirely right. It would be correct to interpret this issue by involving criteria such as disease activity, disability, and life quality.

In conclusion, we recommend fluoroscopyguided sacroiliac joint steroid injections in patients with active sacroiliitis, particularly in those with severe axial pain, for rapid analgesia in the initial term. Furthermore, its is noteworthy that there is a trend to reduce NSAID use in patients receiving these injections, although it does not make a statistically significant difference in the long term.

\section{Declaration of conflicting interests}

The authors declared no conflicts of interest with respect to the authorship and/or publication of this article.

\section{Funding}

The authors received no financial support for the research and/or authorship of this article.

\section{REFERENCES}

1. Braun J, Sieper J, Bollow M. Imaging of sacroiliitis. Clin Rheumatol 2000;19:51-7.

2. Sieper J, Braun J. How important is early therapy in axial spondyloarthritis? Rheum Dis Clin North Am 2012;38:635-42.

3. Wendling D, Claudepierre P, Prati C. Early diagnosis and management are crucial in spondyloarthritis. Joint Bone Spine 2013;80:582-5.
4. Atzeni F, Gianturco L, Talotta R, Varisco V, Ditto MC, Turiel $\mathrm{M}$, et al. Investigating the potential side effects of anti-TNF therapy for rheumatoid arthritis: cause for concern? Immunotherapy 2015;7:353-61.

5. Nanau RM, Neuman MG. Safety of anti-tumor necrosis factor therapies in arthritis patients. J Pharm Pharm Sci 2014;17:324-61.

6. Hartung W, Ross CJ, Straub R, Feuerbach S, Schölmerich J, Fleck M, et al. Ultrasound-guided sacroiliac joint injection in patients with established sacroiliitis: precise IA injection verified by MRI scanning does not predict clinical outcome. Rheumatology (Oxford) 2010;49:1479-82.

7. Wendling D. Local sacroiliac injections in the treatment of spondyloarthritis. What is the evidence? Joint Bone Spine 2020;87:209-13.

8. Rudwaleit M, van der Heijde D, Landewé R, Listing $\mathrm{J}$, Akkoc N, Brandt $\mathrm{J}$, et al. The development of Assessment of SpondyloArthritis international Society classification criteria for axial spondyloarthritis (part II): validation and final selection. Ann Rheum Dis 2009;68:777-83

9. Lambert RG, Bakker PA, van der Heijde D, Weber U, Rudwaleit M, Hermann KG, et al. Defining active sacroiliitis on MRI for classification of axial spondyloarthritis: update by the ASAS MRI working group. Ann Rheum Dis 2016;75:1958-63.

10. Ozgocmen S, Bozgeyik Z, Kalcik M, Yildirim A. The value of sacroiliac pain provocation tests in early active sacroiliitis. Clin Rheumatol 2008;27:1275-82.

11. van der Linden S, Valkenburg HA, Cats A. Evaluation of diagnostic criteria for ankylosing spondylitis. A proposal for modification of the New York criteria. Arthritis Rheum 1984;27:361-8.

12. Maugars $Y$, Mathis $C$, Vilon P, Prost A. Corticosteroid injection of the sacroiliac joint in patients with seronegative spondylarthropathy. Arthritis Rheum 1992;35:564-8.

13. Akkoc Y, Karatepe AG, Akar S, Kirazli Y, Akkoc N. A Turkish version of the Bath Ankylosing Spondylitis Disease Activity Index: reliability and validity. Rheumatol Int 2005;25:280-4.

14. Kviatkovsky MJ, Ramiro S, Landewé R, Dougados M, Tubach F, Bellamy N, et al. The Minimum Clinically Important Improvement and Patient-acceptable Symptom State in the BASDAI and BASFI for Patients with Ankylosing Spondylitis. J Rheumatol 2016;43:1680-6.

15. Maugars Y, Mathis C, Berthelot JM, Charlier C, Prost A. Assessment of the efficacy of sacroiliac corticosteroid injections in spondylarthropathies: a double-blind study. Br J Rheumatol 1996;35:767-70.

16. Karabacakoglu A, Karaköse S, Ozerbil OM, Odev K. Fluoroscopy-guided intraarticular corticosteroid injection into the sacroiliac joints in patients with ankylosing spondylitis. Acta Radiol 2002;43:425-7.

17. Bollow M, Braun J, Taupitz M, Häberle J, Reibhauer $\mathrm{BH}$, Paris $\mathrm{S}$, et al. CT-guided intraarticular 
corticosteroid injection into the sacroiliac joints in patients with spondyloarthropathy: indication and follow-up with contrast-enhanced MRI. J Comput Assist Tomogr 1996;20:512-21.

18. Günaydin I, Pereira PL, Fritz J, König C, Kötter I. Magnetic resonance imaging guided corticosteroid injection of sacroiliac joints in patients with spondylarthropathy. Are multiple injections more beneficial? Rheumatol Int 2006;26:396-400.
19. van der Heijde D, Sieper J, Maksymowych WP, Dougados M, Burgos-Vargas R, Landewé R, et al. 2010 Update of the international ASAS recommendations for the use of anti-TNF agents in patients with axial spondyloarthritis. Ann Rheum Dis 2011;70:905-8.

20. Plastaras CT, Joshi AB, Garvan C, Chimes GP, Smeal $\mathrm{W}$, Rittenberg J, et al. Adverse events associated with fluoroscopically guided sacroiliac joint injections. PM R 2012;4:473-8. 